\title{
Effect of dexamethasone administration on the pathogenicity and lesion severity in rats experimentally inoculated with Orf virus (Malaysian isolates)
}

\begin{abstract}
Contagious ecthyma (Orf) is a viral skin condition caused by a parapoxvirus. It results in cutaneous lesions that destroy the hides and skin of the infected host. In this study, the pathogenicity of Malaysian isolates of Orf virus (UPM 1/14 and UPM 2/14) was evaluated in a rat model using different inoculation sites with/without dexamethasone administration. A total of 50 rats were used in this study. For the first part of the study, 35 rats were divided into three groups; group $1(n=15)$ was inoculated with $0.5 \mathrm{~mL}$ of UPM $1 / 14$ (tissue culture infective dose $50 \%\left(\right.$ TCID $\left.\left._{50}\right) 10^{8.1} / \mathrm{mL}\right)$ while group $2(n=15)$ was inoculated with $0.5 \mathrm{~mL}$ of UPM 2/14 $\left(\operatorname{TCID}_{50} 10^{7.2} / \mathrm{mL}\right)$ each at the dorsum $(n=5)$, ear pinna $(n=5)$, and labial commissure $(n=5)$. Group $3(n=5)$ served as the control and was administered $0.5 \mathrm{~mL}$ of phosphate-buffered saline in all the sites mentioned above. In the second study, 15 rats were divided into three groups: a dexamethasone group $(n=5)$ which was given $10 \mathrm{mg} / \mathrm{kg}$ of dexamethasone once daily for 3 days, a non-dexamethasone group $(n=5)$, and a control $(n=5)$. Intradermal inoculation of $0.5 \mathrm{~mL}$ of UPM $1 / 14$ was administered to each rat in the dexamethasone and non-dexamethasone groups at the dorsum, ear pinna, and labial commissure, respectively. Clinical signs and histopathological changes were evaluated for 14 days post inoculation for the first experiment and 7 days for the second experiment. Mild hyperemia was observed in the dorsum, ear pinna, and labial commissures of all inoculation groups. Group 1 (ORFV UPM 1/14) had a higher $(P<0.05)$ mean skin lesion score and mean stratum spinosum thickness on the labial commissure than group 2 (ORFV UPM 2/14). The dexamethasone-treated group had a higher $(P<0.05)$ mean skin lesion score than the nondexamethasone group. Keratosis, acanthosis, and ballooning degeneration were the most common lesions observed in all inoculation groups. The dexamethasone-treated group had a higher $(P<0.05)$ mean thickness of the stratum spinosum following all inoculation sites than the non-dexamethasone group. There was no significant difference $(P>0.05)$ in the mean thickness of the stratum basale of the ear pinna and labial commissure between the dexamethasone and non-dexamethasone groups. Orf virus was detected by PCR from the skin tissues of rats with lesions using F1L and B2L viral genes. In conclusion, Malaysian isolates of Orf virus were seen to be mildly pathogenic to rats. The difference in inoculation sites and the induction of immune suppression were observed to present varying pathological responses in rats.
\end{abstract}

Keyword: Orf virus; Dexamethasone; Pathogenicity; Immunosuppression 